\title{
Do Socially Responsible Investments Strategies Significantly Reduce Diversification Benefits?
}

\author{
$\underline{\text { S.Z. Abidin }}^{\text {a }}$ and C. Gan ${ }^{\text {a }}$ \\ ${ }^{a}$ Faculty of Agribusiness and Commerce, Lincoln University, P O Box 85084, Lincoln 7647, New Zealand \\ Email: sazali.abidin@lincoln.ac.nz
}

\begin{abstract}
The performance of Socially Responsible Investments (SRI) funds is one of the hottest debate in SRI research. As the process of constructing SRI funds employs many non-financial criteria, the performance of SRI might be influenced because of lack of diversification. With socially responsible consideration, the construction of SRI is restricted by many non-financial criteria. Therefore, the diversification of SRI funds would be reduced in two ways. Firstly, investment may be constrained in certain highly correlated scope. Secondly, some good investment opportunities may be excluded by the non-financial criteria. Using a number of screening criteria to measure the screening intensity, most studies found that the number of screens negatively impacts SRI fund performance. This research is motivated to answer a beleaguering question - do social, ethical, environmental and corporate governance friendly consideration and non-financial criteria employed in screening social responsible investment reduce SRI diversification benefits?
\end{abstract}

There are three research questions answered by this paper. First, this paper studies whether the diversification of SRI funds is significantly different from the diversification of peer conventional funds. Peer conventional funds are selected with matching fund approach by considering fund domicile, year of inception and funds size. Diversification degree of fund in this paper is measured by six variables: the number of stocks, the percentage of top 10 holdings, and asset allocation in cash, bond, and equity. Both Mood's median test and Student's t-test are used in this paper to examine the significance of difference in diversification between SRI funds and peer conventional funds. Second, this paper investigates whether the influence of socially responsible screening criteria on SRI funds diversification is significantly negative. The results of t-test indicate whether the difference in diversification between SRI and conventional funds is significantly negatively. Third, this paper observes the diversification difference between environmental focus SRI funds and environment, social, and governance (ESG) focus SRI funds to determine whether the difference in diversification benefits of these different group of funds (with different screening strategies) is statistically significant. Both Mood's median test and t-test are applied in this part. As the group of environmental focus SRI funds and the group of ESG focus SRI funds are different in size, independent t-test for means is used in this comparison.

Based on maturity of SRI market and data availability, empirical research on social responsible investment is mainly concentrated in the US and some developed European countries. However, economic growth in AsiaPacific region is rapid and prominent, and the SRI markets in Asia are full of potentiality of development. To fill the gap on SRI research and explore SRI developing in emerging market, this study expands SRI research to Asia-Pacific region. This study uses data gathered from Morningstar and Datastream for a period of 13 years from 2004 to 2016 on five Asia-Pacific countries (United States, South Korea, Japan, Australia and China). This paper contributes to the literature on SRI funds in three aspects. First, unlike most studies on SRI funds that focus on performance of SRI funds, this paper highlights the diversification benefits of SRI funds. Second, unlike most studies that focus on US and European markets, this paper expands research in Asia-Pacific region. The five countries selected are top five countries in the Asia-Pacific region that have highest number of socially responsible funds in Morningstar. A total of 721 SRI funds included in this study represents 90 percent of total SRI funds in Asia-Pacific region. Third, this paper provides a cross-country analyses on SRI diversification between the five countries selected. Findings of this paper show that diversification between SRI and conventional funds, as well as, environmental focus SRI funds and ESG focus SRI funds were significantly different, but the influence of SRI screening on fund diversification are not all negative. Such results support findings in some paper on SRI fund performance that SRI funds do not significantly underperform conventional funds.

Keywords: $\quad$ Ethical, investments, fund management, diversification 


\section{INTRODUCTION}

Socially responsible investment (SRI) refers to investment that takes into consideration of social, environmental, ethical and financial dimensions all together (Bian \& Wong, 2013). The development of SRI has religious background, which could be trace back to ancient origins in Jewish, Christian and Islamic traditions (Renneboog, Horst, \& Zhang, 2008b; Derwall, Koedijk, \& Horst, 2011; Berry \& Junkus, 2013). Following a series of social campaigns in 1960s, such as the anti-war movement, investors began to pay attention on social consequences of their investments. The first modern SRI mutual fund was founded in 1971 in the US, which avoids investing in weapon contractors (Renneboog, Horst, \& Zhang, 2008b). In the late 1980s, several terrible environmental disasters, such as the Chernobyl nuclear leakage accident and The Exxon Valdez Oil Spill increased investors' awareness to the negative environmental consequences of industrial development (Renneboog, Horst, \& Zhang, 2008b). Since the early 1990s, the SRI industry has experienced strong growth in the US, Europe, and the rest of the world because of ethical consumerism, which customers are willing to pay extra money for products that are consistent with their personal values (Renneboog, Horst, \& Zhang, 2008b). In recent years, not only issues like environmental protection, human rights, and labour relations have become common consideration in the SRI investment screens, but also criteria like transparency, corporate governance and responsibility have emerged as essential SRI screens.

As the awareness of investors to social, environmental, ethical, and corporate governance issues increasing, SRI has experienced an explosive growth around the world in recent years (Benson \& Humphrey, 2008; Renneboog, Horst, \& Zhang, 2008b; Renneboog, Horst, \& Zhang, 2011 ). The SRI market in the US started early, and has become large and more mature than other countries. Social Investment Forum (SIF) reports that professionally managed assets with SRI strategies have grew by $380 \%$ since 1995 to US\$3.07 trillion in 2010 (2010, as cited in Pérez-Gladish, Benson, \& Faff, 2012; Nofsinger \& Varma,2014). In comparison, general assets under professional management increased only $260 \%$ from US\$7 trillion to US\$25.2 trillion over the same time period (Pérez-Gladish, Benson, \& Faff, 2012; Nofsinger \& Varma, 2014). SRI has more prominent growth during financial crisis period. During the financial crisis (2007-2009), the broad universe of professionally managed assets has remained roughly flat, while SRI strategies assets enjoyed healthy growth of more than $13 \%$ (Nofsinger \& Varma, 2014).

In comparison to US and European markets, SRI markets in Australasia and Asia are young, but are full of potentiality of development. According to Responsible Investment Association Australasia (RIAA), at the end of 2013, responsible investment portfolio increased significantly (by 51.2\%) to AUD\$25 billion, which constituted more than 70 funds. The responsible investment market in New Zealand grew strongly (by 20\%) to reach NZD\$27.0 billion at the end of 2013, which represented a very significant $40 \%$ of total asset under management in New Zealand (RIAA, 2014). Konyn (2011) argued that the nuclear disaster at the Fukushima power plant resulted to investors paying more attention to ESG criteria and made companies focus more intensely on how to communicate with shareholders (Konyn, 2011). According to Association for Sustainable \& Responsible Investment in Asia (ASrIA), sustainable investment fund in Asia has grown by $11 \%$ per annum from 2011 to 2013 to reach a total of 500 funds. Although SRI markets in Asia is still small in size and is still in the early stage of development, there has been a strong growth in both number and size of SRI funds and this trend is expected to be sustained in many years to come (ASrIA, 2014).

\section{PERFORMANCE OF SRI FUNDS}

With socially responsible consideration, the construction of SRI is restricted by many non-financial criteria, which may reduce SRI diversification. According to Renneboog, Horst, and Zhang (2008b), SRI funds apply a set of investment screens to select or exclude assets based on ecological, social, corporate governance or ethical criteria, and often engages in the local communities and in shareholder activism to further corporate strategies. Lee, Humphrey, Benson and Ahn (2010) report that Social Investment Forum (2005) identifies 11 screening criteria that are widely used in practice: alcohol, tobacco, gambling, defence/weapons, animal testing, product/services, environment, human rights, labour relations, equal employment, and community investment. In the research of Renneboog, Horst, and Zhang (2011), there are 21 investment screening criteria widely used by SRI funds around the world, which are classified into four broad categories: sin, ethical, social, and environmental. The screening criteria are sorted by two screening strategies: negative and positive. Negative screens refer to industries that SRI should avoid investing in, such as tobacco, alcohol, gambling, weapons, and pornography, which are so-called "sin industries" (Renneboog, Horst, \& Zhang, 2011). Positive screens are employed to select companies meeting superior standards on issues such as corporate governance or environmental protection (Renneboog, Horst, \& Zhang, 2008a). Mutual funds usually impose negative or positive screens, or a combination of these SRI screens in the process of constructing portfolios (Lee, Humphrey, Benson, \& Ahn, 2010; Renneboog, Horst, \& Zhang, 2011). In 
addition, the use of positive screens is often combined with a "best in class" approach, which means that firms are ranked within each industry based on social criteria, and only those firms passing a minimum threshold in each industry are selected as potential candidates for inclusion in a portfolio (Renneboog, Horst, \& Zhang, 2008a). Therefore, the diversification of SRI funds would be weakened in two reasons. Firstly, investment may be constrained in certain highly correlated scope. Secondly, some good investment opportunities may be excluded by the non-financial criteria.

Renneboog, Horst, and Zhang (2008a) apply a unique dataset consisting of nearly all SRI mutual funds around the word, which includes the US, the UK, most continental European and Asia-Pacific countries. The study finds that fund returns decrease with screening intensity on social and corporate governance criteria. The result is consistent with the underperformance hypothesis of SRI funds that high SRI screening intensity constrains the risk-return optimization and does not help fund managers to pick up underpriced stocks (Renneboog, Horst, \& Zhang, 2008a). Using abnormal return, Lee, Humphrey, Benson and Ahn (2010) discover that performance is reduced by 70 basis points for each additional screen imposed by the fund. Humphrey and Lee (2011) investigate the performance and risk of SRI equity funds in the Australian market and found that negative screening significantly increases risk and reduces fund's ability to form diversified portfolios. In Capelle-Blancard \& Monjon (2014), the study assesses the financial performance within SRI mutual funds in France and concludes that in overall, there is a cost associated with the SRI screening process since the financial performance of SRI is reduced by the exclusion of non-socially responsible stocks.

The difference in performance between SRI and conventional funds has been extensively researched (GilBazo, Ruiz-Verdú, \& Santos, 2010; Rathner, 2013). Match fund approach that matches SRI funds with conventional funds commonly of similar fund size, age, religious, industry or fee composition are widely used in SRI empirical research (Renneboog et al, 2011; Chegut, Schenk, \& Scholtens, 2011; Nofsinger \& Varma, 2014). However, the results are mixed and most empirical results show that there is no significant difference between the performance of SRI funds and conventional funds. Nofsinger and Varma (2014) found that compared to conventional mutual funds, socially responsible mutual funds outperformed during period of market crises. However, when observing SRI fund in the US, the UK, and in many conventional European and Asia Pacific countries, Renneboog, Horst, and Zhang (2008a) found evidence that investors are paying a price for ethics as such that SRI funds underperformed their domestic benchmarks by between $2.2 \%$ and $6.5 \%$. Moreover, when comparing risk-adjusted returns of the SRI funds with those of peer conventional funds in France, Japan and Sweden, Renneboog, Horst, and Zhang (2008a) documented that the risk-adjusted returns of SRI funds are not statistically different from the performance of conventional funds. Gil-Bazo et al.(2010) found a significant outperformance of US SRI funds based on a four-factor-model. To evaluate the difference in performance between SRI funds and conventional mutual funds, Arvidsson, and Ljungbergh (2015) use Jasen's alpha to measure risk-adjusted performance and apply CAPM and Carhart's four-factor model to Swedish dataset and conclude that there is no significant difference in performance between the two types of funds during a period of ten years from 2005 to 2015. In addition, using Marginal Conditional Stochastic Dominance to compare the performance of the UK SRI funds and conventional funds, Clark, Deshmukh, \& Belghitar (2015) did not find any significant difference in the performance between the two types of funds.

\section{DIVERSIFICATION OF SRI FUNDS}

Blancard and Monjon (2010) found that performance and diversification are the most common two topics in newspapers and academic journals during 1982-2009 in term of SRI financial characteristics. From 1980s to 2000 s, attention to SRI diversification, in newspapers, significantly increased by $2.1 \%$ (Blancard \& Monjon, 2010) and 4.7\% in academic journals. According to Cortez, Silva, and Areal (2012, p. 225), the issue of diversification can be quite important in the particular case of socially responsible funds. One of the arguments that is usually used to hypothesize why socially responsible funds should underperform conventional funds is that these portfolios are based on a more restricted investment opportunity set. Linking the classical financial portfolio theory to the process of identifying SRI portfolios, many researchers express their worries about SRI diversification (Benson \& Humphrey, 2008; Lee, Humphrey, Benson, \& Ahn, 2010; Chegut, Schenk, \& Scholtens, 2011; Lean, Ang, \& Smyth, 2014).

Modern portfolio theory suggests that, in order to maximize the expected return of the portfolio by spreading risk, an efficient portfolio should consist of diversified and non-correlated stocks. However, an SRI portfolio represents a less diversified portfolio due to the screening process during the portfolio formation (Lean, Ang, \& Smyth, 2014). Chegut, Schenk and Scholtens (2011) argued that portfolio theory implies that restrictive criteria constrain an investor's investment possibilities and this results to lower diversification and greater risk exposure or additional cost. Benson and Humphrey (2008) reflect that as the investment opportunity set 
is constrained by the non-financial criteria and a mean-variance efficient portfolio may not be achievable, an SRI portfolio is expected to under-perform a conventional portfolio. Based on the lack of diversification hypothesis, Capelle-Blancard and Monjon (2014) found that the coefficient associated with the number of screens is negative and significant at the $5 \%$ level.

\section{DATA AND METHODOLGY}

\section{1. $\quad$ SRI funds and conventional funds}

This study identifies 721 socially responsible funds in the Asia-Pacific region during the period 2004-2016. Fund domicile includes the US, South Korea, Australia, Japan and China. According to socially conscious funds database in Morningstar, these are top five countries in the Asia-Pacific region that have the highest number of socially responsible funds. SRI funds from the five countries represent $90 \%$ of SRI funds in the Asia-Pacific region in 2016. The number of SRI fund in the rest of the countries are in single digits. All of the SRI funds in this study are open-ended funds. According to Morningstar, all socially conscious funds are classified into four groups: religious focus, Shariah focus, environmental focus, and ESG focus. In the study sample, most SRI funds are environmental focus or ESG focus. This study will not only examine the diversification difference between SRI and conventional funds, but also investigates the diversification difference between environmental focus SRI funds and ESG focus SRI funds.

Matching fund approach has been widely used in studies that investigate SRI characteristics and performance (Renneboog et al, 2011; Nofsinger \& Varma, 2014). This approach matches SRI funds with conventional non-SRI funds, which are similar to SRI funds in fund size, age, region, industry, asset allocation, and fee composition. Fund size and age are most common used properties in empirical research. Firstly, this paper chooses conventional funds which domicile is as same as matched SRI fund. Secondly, this paper looks at inception date, selecting the fund that its inception year within one year of the SRI fund's inception data. Finally, a conventional fund would be selected with adequate data availability and smallest fund size different from matched SRI fund. This process is similar to Nofsinger and Varma (2014) did in their study. All conventional funds are collected from Morningstar global open-ended funds database. The summary of SRI and peer conventional funds is showed in Table 1.

Table 1. Summary of SRI funds and conventional funds

\begin{tabular}{|l|c|c|c|c|}
\hline \multicolumn{1}{|c|}{ Country } & Environmental focus & ESG focus & Total SRI funds & Conventional funds \\
\hline United States & 51 & 369 & 420 & 420 \\
\hline South Korea & 91 & 60 & 151 & 151 \\
\hline Australia & 2 & 55 & 57 & 57 \\
\hline Japan & 29 & 39 & 68 & 68 \\
\hline China & 6 & 19 & 25 & 25 \\
\hline Total & 179 & 542 & 721 & 721 \\
\hline
\end{tabular}

\subsection{Measure of diversification}

In many studies, the number of stocks is one of the most widely used measure for portfolios, or mutual funds diversification. Domian, Louton, and Racine (2007) found that the average standard deviation of returns of portfolios composed of only one stock was $49.2 \%$, while the average portfolio risk could reduce to $19.2 \%$ with diversification, when the number of stocks in the portfolio increased. Several research studies have suggested that a strong risk reduction of holdings can be realizes by increasing the number of stocks, and the number of stocks held by a fund is a sample measure of the degree of diversification (Domian et al., 2003, 2007; Sapp and Yan, 2008, as cited in Hu, Chang, \& Chou, 2014).

However, considering the number of stocks held may not fully reflect the dispersion of holding. Kaushit and Barnhart (2009), and Hu, Chang, and Chou (2014) suggested the use of the percentage of assets invested in the top 10 holdings of a fund as a diversification measure. This paper applies the number of stocks, as well as, the percentage assets in the top 10 holdings to measure mutual funds diversification. In addition, recognizing that different types of assets have different characteristics exposed to risk, this paper also considers asset allocation (using percentage of cash, bond, and equity) as other measure of diversification. Therefore, diversification in this paper is measured by five variables: the number of stocks, the percentage of top 10 holdings, the percentage of cash, the percentage of bond, and the percentage of equity. All data are is derived from Morningstar. 


\section{3. $\quad$ Research models}

Mood's median test is a nonparametric test that determines whether the medians of two independent samples are equal. Mood's median test is widely used in comparing two groups difference (Athanassakos, 2013; Chen, 2015). As the Mood's median test is particularly appropriate in the preliminary stages of analysis, and the results of Mood's median test would only show the significance between differences without positive or negative indicator, this paper will use Mood's median test at the first stage, to investigate whether SRI and peer conventional funds, as well as environmental focus SRI funds and ESG focus SRI funds, are significant difference in diversification. Subsequently, t-test is used to explore whether the influence of socially responsible consideration on funds diversification is negative. Therefore, Mood's median test would answer research question of this paper at the first stage on whether socially responsible consideration and screening strategies make SRI funds different in diversification. Further analysis would be enriched by t-test.

The t-test assesses whether the means of two groups are statistically different from each other. In this paper, SRI funds and peer conventional funds are selected within same domicile, year of inception, and similar range of fund size. In each of the sample country, the number of date points for SRI funds and peer conventional funds are equal. So, it is appropriate to apply paired t-test to test diversification difference between SRI and peer conventional funds. However, in this paper, the group of environmental focus SRI and the group of ESG focus SRI are independent. As such, in examining whether diversification of SRI funds with environmental focus and SRI funds with ESG focus are significantly different, independent t-test is employed since independent t-test is the most appropriate test for means where data are collected from two random samples of independent observations.

\section{DISCUSSION AND CONCLUSIONS}

Table 2 reports the summary statistics for all variables that were used to measure the degree of diversification for the whole sample of countries included in this study. The measures are mean, standard deviation, number of observations, minimum, maximum, and median. There is a total of 4,751 observations of socially responsible funds in this study. Among 4,751 SRI observations, there are 959 environmental focus SRI observations, and 3,792 ESG focus SRI funds. To comparing diversification difference between SRI and conventional funds, 4,751 conventional observations are selected. Panel A reports the summary statistic for all SRI funds.

The descriptive statistics for all peer conventional funds are showed in Panel D. Comparing mean and median values in panel $A$ with those in panel $D$, this paper observes that mean and median values in SRI funds are much smaller than those in conventional funds in term of top 10 holdings, percentage of bonds and percentage of other. Regarding to the number of stocks, asset allocation in cash and equity, this paper finds that the means and medians of SRI funds are quite larger than those of conventional funds. As this paper is going to explore diversification difference in different SRI screening strategies, Panel B and C present summary statistics for environmental focus SRI funds and ESG focus SRI funds respectively. Comparing observations between environmental and ESG focus funds, it reveals that about one fifth SRI funds in the Asia-Pacific region are environmental focus, while ESG focus SRI in Asia-Pacific occupy four fifth shares.

This paper finds that diversification of SRI and conventional funds are different significantly in the number of stock, the percentage of top 10 holdings, asset allocation in cash, bond, and equity in the whole AsiaPacific region sample. Such characteristics is prominent both in environmental focus SRI funds and ESG focus SRI funds. In addition, the difference in the number of stock, top 10 holdings, percentage of bond, and equity are highly significant in the whole Asia-Pacific region sample at $1 \%$ level. This paper also finds that environmental focus SRI funds invest much less in bond than ESG focus funds. The mean difference in percentage of bond between environmental focus and ESG focus are all negative and significant in each of the sample countries.

Through mood's median test, this paper finds that SRI and peer conventional funds are significantly different in the number of stocks, percentage of top 10 holdings, asset allocation in cash, bond, and equity. In the whole Asia-Pacific sample, all six variables of measuring diversification are significant at $1 \%$ level. Such results appear not only when comparing all SRI funds to peer conventional funds, but also arise when comparing environmental focus SRI funds to conventional funds, and ESG focus SRI funds to conventional funds respectively. 
Abidin and Gan, Do Socially Responsible Investments Strategies Significantly Reduce Diversification Benefits?

Table 2. Descriptive statistics - 2006-2016

\begin{tabular}{|c|c|c|c|c|c|c|}
\hline & Mean & Std.Dev. & $\mathbf{N}$ & Min & $\operatorname{Max}$ & Median \\
\hline \multicolumn{7}{|c|}{ Panel A: All SRI funds } \\
\hline No. of stocks & 99.38 & 249.68 & 4,751 & 0.00 & $3,139.00$ & 45.00 \\
\hline Top 10 holdings & 42.39 & 28.18 & 4,751 & -42.92 & 150.26 & 33.51 \\
\hline Cash \% & 5.42 & 12.16 & 4,751 & -155.61 & 100.00 & 3.36 \\
\hline Bond $\%$ & 14.25 & 31.07 & 4,751 & -0.03 & 246.46 & 0.00 \\
\hline Equity $\%$ & 77.86 & 34.16 & 4,751 & -0.52 & 212.59 & 94.89 \\
\hline \multicolumn{7}{|c|}{ Panel B: Environmental focus SRI funds } \\
\hline No. of stocks & 67.46 & 273.53 & 959 & 0.00 & 2778.00 & 32.00 \\
\hline Top 10 holdings & 59.24 & 30.51 & 959 & -18.20 & 123.91 & 49.04 \\
\hline Cash \% & 8.10 & 13.79 & 959 & -116.34 & 100.00 & 4.89 \\
\hline Bond $\%$ & 2.02 & 9.83 & 959 & 0.00 & 74.80 & 0.00 \\
\hline Equity \% & 86.22 & 24.12 & 959 & 0.00 & 212.59 & 93.63 \\
\hline \multicolumn{7}{|c|}{ Panel C: ESG focus SRI funds } \\
\hline No. of stocks & 107.46 & 242.65 & 3,792 & 0.00 & $3,139.00$ & 49.00 \\
\hline Top 10 holdings & 38.13 & 25.89 & 3,792 & -42.92 & 150.26 & 30.53 \\
\hline Cash \% & 4.75 & 11.62 & 3,792 & -155.61 & 89.70 & 3.00 \\
\hline Bond $\%$ & 17.34 & 33.73 & 3,792 & -0.03 & 246.46 & 0.00 \\
\hline Equity \% & 75.74 & 35.95 & 3,792 & -0.52 & 112.19 & 95.18 \\
\hline \multicolumn{7}{|c|}{ Panel D: All conventional funds } \\
\hline No. of stocks & 84.58 & 255.89 & 4,751 & 0.00 & $4,818.00$ & 35.00 \\
\hline Top 10 holdings & 48.41 & 47.04 & 4,751 & -122.68 & 1247.49 & 37.06 \\
\hline Cash \% & 4.64 & 63.27 & 4,751 & -2113.15 & 101.06 & 3.27 \\
\hline Bond $\%$ & 23.22 & 45.12 & 4,751 & -7.26 & 905.30 & 0.00 \\
\hline Equity $\%$ & 66.71 & 43.94 & 4,751 & -94.41 & 644.58 & 91.24 \\
\hline
\end{tabular}

After analyzing results of t-test for means between environmental focus and ESG focus SRI funds, this paper summarizes that different SRI strategies has significant influence on SRI funds diversification. In paired ttest for means between SRI and peer conventional funds, this paper finds that in term of the number of stocks and the percentage of equity, SRI funds are significantly larger than peer conventional funds. In top 10 holdings and percentage of bonds, SRI funds are significantly smaller than peer conventional funds. Such results not only were found in comparison between all SRI and conventional funds, but also in group of either environmental focus SRI funds, or ESG focus SRI funds compared to peer conventional funds. Such results indicate that SRI screening strategies have significant influence on funds diversification.

Comparing environmental focus SRI funds with ESG focus SRI funds, this paper finds that they are significantly different in the number of stocks, asset allocation in cash, bond, and equity. In Mood's median test, the difference in the percentage of equity is particularly prominent than other measure of diversification. In independent t-test, the percentage of equity is significantly positive at $1 \%$ level in the Asia-Pacific sample, United States and China, while the percentage of bond is significantly negative at $1 \%$ level. This indicates that environmental focus SRI funds allocate more investments in equity rather than bond.

In summary, this paper finds that SRI strategies have significant influence on funds diversification. However, the influence is not entirely negative in all measure of diversification. In Asia-Pacific region, the empirical results indicate that the diversification between SRI and conventional funds are significantly different. The results support findings in some existing studies on performance of SRI funds that SRI fund performance is no better or worse than that of conventional funds. 
Abidin and Gan, Do Socially Responsible Investments Strategies Significantly Reduce Diversification Benefits?

\section{REFERENCES}

Arvidsson, U., \& Ljungbergh, E. (2015). Socially Responsible Investments: Are investors paying a price for investing ethically?.

ASrIA. (2014). 2014 Asia Sustainable Investment Review. Retrieved from http://asria.org/wpcontent/uploads/2014/12/2014-Asia-Sustainable-Investment-Review1.pdf

Athanassakos, G. (2013). Are Negative P/E and P/B ratio Firms Different?. Journal of Business \& Financial Affairs.

Benson, K. L., \& Humphrey, J. E. (2008). Socially responsible investment funds: Investor reaction to current and past returns. Journal of Banking \& Finance, 32(9), 1850-1859. doi:10.1016/j.jbankfin.2007.12.013

Berry, T. C., \& Junkus, J. C. (2013). Socially responsible investing: An investor perspective. Journal of business ethics, 112(4), 707-720.

Bian, S. X., \& Wong, V. (2013). An Examination of the Diversification Benefits of SRI in a Portfolio Context. Journal of Energy Technologies and Policy, 3(11), 397-407.

Capelle - Blancard, G., \& Monjon, S. (2014). The performance of socially responsible funds: does the screening process matter?. European Financial Management, 20(3), 494-520.

Chegut, A., Schenk, H., \& Scholtens, B. (2011). Assessing SRI fund performance research: Best practices in empirical analysis. Sustainable Development, 19(2), 77-94.

Cortez, M. C., Silva, F., \& Areal, N. (2012). Socially responsible investing in the global market: The performance of US and European funds. International Journal of Finance \& Economics, 17(3), 254-271.

Derwall, J., Koedijk, K., \& Ter Horst, J. (2011). A tale of values-driven and profit-seeking social investors. Journal of Banking \& Finance, 35(8), 2137-2147.

Domian, D. L., Louton, D. A., \& Racine, M. D. (2007). Diversification in portfolios of individual stocks: 100 stocks are not enough. Financial Review,42(4), 557-570.

Gil-Bazo, J., Ruiz-Verdú, P., \& Santos, A. A. P. (2010). The performance of socially responsible mutual funds: The role of fees and management companies. Journal of Business Ethics, 94(2), 243-263. doi:10.1007/s10551-009-0260-4

Hu, J. L., Chang, T. P., \& Chou, R. Y. (2014). Market conditions and the effect of diversification on mutual fund performance: should funds be more concentrative under crisis?. Journal of Productivity Analysis, 41(1), 141151.

Humphrey, J. E., \& Lee, D. D. (2011). Australian socially responsible funds: Performance, risk and screening intensity. Journal of Business Ethics, 102(4), 519-535. doi:10.1007/s10551-011-0836-7

Kaushik, A., \& Barnhart, S. W. (2009). Do mutual funds with few holdings outperform the market? The Journal of Asset Management, 9(6), 398-408. doi:10.1057/jam.2008.39

Konyn, M. (2011). Asia focus turns to social responsibility. Retrieved from http://www.ft.com/intl/cms/s/0/5a505504-7d8d-11e0-b418-00144feabdc0.html\#axzz3eyluGmrB

Lean, H. H., Ang, W. R., \& Smyth, R. (2014). Performance and Performance Persistence of Socially Responsible Investment Funds in Europe and North America.

Lee, D. D., Humphrey, J. E., Benson, K. L., \& Ahn, J. Y. K. (2010). Socially responsible investment fund performance: The impact of screening intensity. Accounting and Finance, 50(2), 351-370. doi:10.1111/j.1467-629X.2009.00336.x

Lee, W. (2011). Risk-based asset allocation: A new answer to an old question? The Journal of Portfolio Management, 37(4), 11-28.

Nofsinger, J., \& Varma, A. (2014). Socially responsible funds and market crises. Journal of Banking \& Finance, 48, 180-193. doi:10.1016/j.jbankfin.2013.12.016

Pérez-Gladish, B., Benson, K., \& Faff, R. (2012). Profiling socially responsible investors: Australian evidence. Australian Journal of Management, 37(2), 189-209.

Renneboog, L., Horst, J., \& Zhang, C. (2008 $)$. The price of ethics and stakeholder governance: The performance of socially responsible mutual funds. Journal of Corporate Finance, 14(3), 302-322. doi:10.1016/j.jcorpfin.2008.03.009

Renneboog, L., Horst, J., \& Zhang, C. $\left(2008^{b}\right)$. Socially responsible investments: Institutional aspects, performance, and investor behavior. Journal of Banking and Finance, 32(9), 1723-1742. doi:10.1016/j.jbankfin.2007.12.039.

Renneboog, L., Horst, J., \& Zhang, C. (2011). Is ethical money financially smart?: Nonfinancial attributes and money flows of socially responsible investment funds. Journal of Financial Intermediation, 20(4), 562-588. doi:10.1016/j.jfi.2010.12.003.

RIAA. (2014). 2014 Responsible Investment Bechmark Report Australia and New Zealead. Retrieved from http://www.responsibleinvestment.org/wp-content /uploads/2014/08/RIAABenchmark2013_v3b.pdf 